\section{B A Institute of \\ YK Business Administration \\ 页下 \\ Karachi \\ Leadership and Ideas for Tomorrow}

\section{Business Review}

Volume 3 Issue 1 January-June 2008

$1-1-2008$

\title{
On nonlinearities in KSE 100 index stock return
}

Khurshid M. Kiani

Bang College of Business, Almaty, Republic of Kazakhstan

Follow this and additional works at: https://ir.iba.edu.pk/businessreview

Part of the Finance and Financial Management Commons

c) (i)

This work is licensed under a Creative Commons Attribution 4.0 International License.

\section{Recommended Citation}

Kiani, K. M. (2008). On nonlinearities in KSE 100 index stock return. Business Review, 3(1), 79-90.

Retrieved from https://doi.org/10.54784/1990-6587.1134

This article is brought to you by iRepository for open access under the Creative Commons Attribution 4.0 License and is available at https://ir.iba.edu.pk/businessreview/vol3/iss1/8. For more information, please contact irepository@iba.edu.pk. 


\title{
ARTICLE
}

\section{On Nonlinearities in KSE 100 Index Stock Returns}

\author{
Khurshid M. Kiani \\ Bang College of Business, Almaty, Republic of Kazakhstan
}

\begin{abstract}
:
This research investigates possible existence of asymmetries in business cycle fluctuations in Karachi Stock Exchange (KSE) 100 index over money market rates. I model the relationship between excess stock return in KSE 100 index using a number of nonlinear time series models for constructing linearity tests for testing linearity in KSE 100 excess returns. These tests include Keenan test, Ramsay RESET test, and its improved versions i.e. RESET1 and RESET2 tests.

The results based on Keenan test show statistically significant evidence of nonlinearities in KSE 100 excess returns. Likewise the results from Ramsay RESET test confirm this behavior. However, the results from RESET1 test fail to reveal statistically significant evidence of nonlinearities in KSE 100 excess returns. Similarly, RESET2 test failed to reject the linearity hypothesis for KSE 100 index excess returns.
\end{abstract}

Key phrases: asymmetries; nonlinearities; principal components; excess stock returns;

JEL codes: $\quad$ B22, C32, C45, E32;

Word count: Main text - 2065

\section{INTRODUCTION}

It is imperative to detect business cycle asymmetries in macroeconomic and financial time series data for several reasons. For example, nonlinearities in macro-financial variables would imply that the effects of monetary policy and other shocks on output and other macroeconomics and financial time series variables are not symmetric. This means that nonlinearities would invalidate the measure of the persistence of the monetary policy and other shocks on output and the other variables that are based on linear models. This implies that one would not be able to observe the impact of the monetary policy shocks on output and the other coherent variables when the underlying data generating process is nonlinear. This is very important for the policymakers who would be interested in forecasting the impact of the monetary policy and the other shocks on output other time series variables of prime importance in addition to the periods of high and low stock returns volatility. Likewise, it might 
be of interest to identify the candidate time series variables that might include stock returns to help predict future recessions.

A number of researchers undertook studies on business cycle asymmetries using macroeconomic time series. In this context those who employed univariate nonlinear time series models to show the existence of asymmetric business cycle fluctuations in macroeconomic time series include Neftici (1984), Beaudry and Koop (1993), Potter (1995), Ramsey and Rothman (1996), Brunner (1997), Bidarkota (1999-2000), and Kiani and Bidarkota (2004). Similarly, Anderson and Vahid (1998), Anderson and Ramsey (2002) and Andreano and Savio, (2002) employed multivariate nonlinear time series models to conclude that business cycles asymmetries do exist in macroeconomic time series they studied. Likewise, Kiani (2005) and Kiani et al. (2005) used artificial neural networks to conclude that significant business cycle asymmetries do exist in macro-financial time series in the group of seven industrialized (G7) countries they studied. However, this type of research has not yet been focused on business cycle asymmetries in stock returns although study by Gabriel and Timmermann (2001) on business cycle asymmetries in stock returns is an exception.

I feel that the time series models developed and employed to detect business cycle asymmetries in macroeconomic time series be used in detecting business cycle asymmetries in other macro-financial variables of prime importance including stock return especially in an emerging stock market. In particular, I use such models to detect asymmetries in KSE100 stock price index over money market rates. I believe that while focusing on an emerging stock market the present study will fill this gap adequately. Therefore, in this paper I investigate possible existence of business cycle asymmetries in KSE100 excess stock returns using a number nonlinear time series models.

The remaining study is organized in the following sub-sections. Section 2 discusses empirical models that include nonlinear and switching time series models. Section 3 provides empirical results including specification search, parameter estimates, section 4 discusses hypotheses tests, results on hypotheses tests and discussions on results. Finally section 5 provides important conclusions that can be drawn from this study.

\section{EMPIRICAL MODELS}

In this research I employ four types of nonlinear time series models to construct nonlinearity tests for detecting possible existence of asymmetries in KSE100 excess returns series. These tests are designed for testing departures from linearity in mean that are elaborated in the following sub-sections. 
I prefer to employ Schwarz Bayesian Criterion (SBC) for selecting our model parameterizations which is recommended by Schwarz (1978) compared to Akaike Information Criterion (AIC) that is proposed by Judge et al. (1985) because SBC penalizes heavily for inclusion of miss-specified variables.

\subsection{KEENAN TEST}

This linearity test was proposed by Keenan D. M. (1985) which comprises of four parts. In the first part this test a linear model is estimated regressing excess returns series $\left(y_{t}\right)$ on an intercept and its lags $\left(1, y_{s-1}, y_{s-2}, \ldots ., y_{s-M}\right)$ to recover predictions $\left(y h a t=f_{t}\right)$, residuals $\left(\hat{u}_{t}\right)$, and residual sum of squares $\left(S S E_{1}=\sum_{t=1}^{T} \hat{u}_{t}\right)$. In the second part squared predictions from linear model $\left(f_{t}^{2}\right)$ are regressed on an intercept and the past values of the excess returns series $\left(1, y_{s-1}, y_{s-2}, \ldots ., y_{s-M}\right)$ to compute residuals $\left(\hat{v}_{t}\right)$. In the third step, $\hat{u}_{t}\left(\hat{u}_{M+1}, \ldots . ., \hat{u}_{n}\right)$ are regressed on $\hat{v}_{t}\left(\hat{v}_{M+1}, \ldots . ., \hat{v}_{n}\right)$ to estimate $\hat{\eta}_{0}$ and predictions ( $\hat{\eta}$ ) using Equation 2.1 .

$$
\hat{\eta}=\hat{\eta}_{0}\left(\sum_{t=M+1}^{n} v_{t}^{2}\right)^{1 / 2}
$$

The test statistics for this test is calculated using Equation 2.2 and $S S E_{1}$ and $\hat{\eta}$ obtained from the previous step.

$$
T S=\left(\hat{\eta}^{2}(n-2 M-2)\right) /\left(S S E_{1}-\hat{n}^{2}\right)
$$

Under normality hypothesis this test statistics is distributed $F(1, n-2 M-2)$ degrees of freedom. This test examines if squared forecast has any additional predictability. Therefore, the test is designed to test departures from linearity in mean.

\subsection{RAMSEY RESET TEST}

The Ramsey RESET test that was proposed by Ramsey (1969) is an improvement over the Keenan test in an alternate manner because of the form of the model employed in this test. The test consists of three parts. In the first part excess return series $\left(y_{t}\right)$ are regressed on the past values of the series $\left(1, y_{t-1}, \ldots \ldots, y_{t-k}\right)$ for $k=1, \ldots \ldots, p$ to recover predictions $\left(\hat{y}_{t}\right)$, residuals $\left(\hat{u}_{t}\right)$, and residual sum of 
squares $\left(S S E_{0}=\sum_{t=1}^{T} \hat{u}_{t}\right)$ for $t=1, \ldots \ldots ., T$. In the second part of this test, excess returns series are now regressed on perditions from the first part $\left(\hat{y}_{t}=f_{t}{ }^{1}\right)$, and polynomials of these predictions using Equation 2.3 for any $k \geq 2$ to recover residuals $\left(\hat{v}_{t}\right)$, and residual sum of squares $\left(S S E_{1}=\sum_{t=1}^{T} \hat{v}_{t}\right.$ ), for $t=1, \ldots ., T$.

$$
y_{t}=f_{t}+\beta_{1} f_{t}^{2}+\beta_{2} f_{t}^{3}+\ldots \ldots \ldots+\beta_{k} f_{t}^{k}+v_{t}
$$

In the last part of the test, test statistics is computed using Equation 2.4

$$
T S=\left(\left(S S E_{0}-S S E_{1}\right) /(k-1)\right) /\left(S S E_{0} /(n-k)\right)
$$

In Equation 2.4, $k$ denotes the number of the polynomials of forecasts and $n$ the number of observations in the series. The test statistics is distributed approximately $F$ under normality hypothesis with $k-1$, and $n-k$ degrees of freedom. The RESEST tests are responsive for departures from linearity in mean.

\subsection{RESET1 TEST}

RESET1 test is an improved version of RESET test wherein the collinearity between the repressors is avoided using principal component analysis. In the first part of this test excess returns series $\left(y_{t}\right)$ is regressed on an intercept and its lagged values $\left(1, y_{t-1}, \ldots \ldots, y_{t-k}\right)$ for $k=1, \ldots \ldots, p$ to recover predictions $\left(\hat{y}_{t}\right)$, residuals $\left(\hat{u}_{t}\right)$, and residual sum of squares $\left(S S E_{0}=\sum_{t=1}^{T} \hat{u}_{t}\right)$ for $t=1, \ldots \ldots, T$. To avoid collinearity between the data matrix $\left(\tilde{X}_{t}\right)$ and predictions, principal component of the prediction series $\left(f_{t}^{2}, \ldots \ldots \ldots . ., f_{t}{ }^{k}\right)$ for $p^{*}<(k-1)$ are computed. In the third part, predictions $\left(\hat{y}_{t}\right)$ from the previous part are regressed on $\tilde{X}_{t}$ and the principal components $\left(p_{t}^{1}, \ldots \ldots \ldots, p_{t}^{k}\right)$ using Equation 2.5 to recover residuals $\left(\hat{v}_{t}\right)$, and residual sum of squares $\left(S S E_{2}=\sum_{t=1}^{T} \hat{v}_{t}\right)$ for $t=1, \ldots, T$. 


$$
y_{t}=f_{t}+\beta_{1} p_{t}^{1}+\beta_{2} p_{t}^{2}+\ldots \ldots \ldots+\beta_{k} p_{t}^{k}+v_{t}
$$

Finally, test statistics is calculated using Equation 2.8.

$$
\left.T S=\left(\left(S S E_{2}-S S E_{1}\right) / p^{*}\right)\right) /\left(S S E_{2} /(n-k)\right)
$$

where, in Equation 2.6, $n$ is the number of observations, $k$ is the number of variables in the model, $n$ and $p^{*}$ is the number of principal components. The test statistics is distributed approximately $F$ with $p^{*}$ and $n-k$ degrees of freedom under normality hypothesis.

\subsection{RESET2 TEST}

RESET2 test is a Lagrange multiplier version of RESET test wherein collinearity is eliminated using principal components analysis in the test. This test comprises of four parts. In the first part, a linear model is employed to regress excess returns series $\left(y_{t}\right)$ on an intercept and lags of the series to compute predictions $\left(\hat{y}_{t}=f_{t}^{1}\right)$, residuals $\left(\hat{u}_{t}\right)$, and residual sum of squares $\left(S S E_{1}=\sum_{t=1}^{T} \hat{u}_{t}\right)$ for $k=1, \ldots \ldots ., p$, and $t=1, \ldots \ldots \ldots, T$. In the second part, principal components are computed using predictions $\left(f_{t}^{2}, \ldots \ldots ., f_{t}^{k}\right)$ choosing $p^{*}<(k-1)$ to avoid collinearity between the prediction series and data matrix $\left(\tilde{X}_{t}\right)$. In the third part, residuals $\left(\hat{u}_{t}\right)$ from the previous part are regressed on principle components $\left(p_{t}^{1}, \ldots \ldots \ldots, p_{t}^{k}\right)$ and data matrix ( $\tilde{X}_{t}$ ), using Equation 2.7 to compute $R^{2}$.

$$
y_{t}=f_{t}+\beta_{1} p_{t}^{1}+\beta_{2} p_{t}^{2}+\ldots \ldots \ldots+\beta_{k} p_{t}^{k}+v_{t}
$$

In the last part, test statistics is calculated using Equation 2.8 .

$$
T S=n R^{2}
$$

where, in Equation $2.8 n$ is the number of the observations in the series being investigated and the test statistics is distributed $\chi^{2}\left(p^{*}\right)$ under linearity hypothesis. 


\section{EMPIRICAL RESULTS}

\subsection{DATA SOURCES}

Monthly data on KSE 100 stock price index from February, 1989 to February, 2007 along with the money market rates for the corresponding period are used to calculate excess returns series employed in this research. Excess returns are reported as percent per month though out the study. Figure 1 show plots of the KSE100 index excess return series.

\section{HYPOTHESES TESTS}

The chief hypothesis of this study is the hypothesis of linearity versus the alternative hypothesis of nonlinearity. Using linearity tests constructed from nonlinear time series models, this study perform four types of linearity tests. The first type of hypothesis is based on Keenan test, the second on Ramsay RESET test, the third on RESET1 test, and the fourth on RESET2 test. Therefore, for testing possible existence of nonlinearities I test the null hypothesis of linearity against the alternative hypothesis of nonlinearity in KSE100 excess returns series. If the null hypothesis of linearity is true, linearity does prevail in the data series being tested. However, when the null is rejected in favor of the alternative hypothesis, nonlinearities do prevail in the series being tested. These tests are designed to test for departure from linearity in mean.

\subsection{RESULTS ON HYPOTHESES TESTS}

The empirical results on hypotheses tests for Keenan test, Ramsay RESET test, RESET1 test, and RESET2 test are presented in Table 4 . The relevant p-values from $F$ statistics for Keenan, Ramsay RESET test, and RESET1 test, and p-values from $\chi^{2}$ distributions for RESET2 test are juxtaposed in the subsequent column in parenthesis.

The Keenan test as well as Ramsay RESET test reject linearity hypothesis against the alternative hypothesis of nonlinearities for KSE100 stock price index based on the relevant p-values obtained for both the tests from $F$ distributions. However, RESET1 does not reject the null of linearity against the alternative hypothesis of nonlinearity for KSE100 stock price index using p-values from the $F$ distributions. Likewise based on the p-values obtained from $\chi^{2}$ distributions the RESET2 test also fails to reject linearity hypothesis in KSE 100 index excess returns. 
All statistical inferences for these tests are drawn at 5 percent level of significance. The results do not change when I change the significance level from 5 percent to 10 percentage level.

\subsection{DISCUSSION OF RESULTS ON HYPOTHESES TESTS}

Our results for nonlinearity tests based on time series models presented in Table 1 show that two out of the four nonlinear time series models employed to test linearity hypothesis for testing nonlinearities in KSE100 index excess return i.e. Keenan test and Ramsay RESET test show statistically significant evidence of nonlinearities in KSE 100 stock excess returns whereas the other two i.e. RESET1 and RESET2 do not. A plausible of reason of which could be because the models that accepted linearity hypotheses were not able to pick the type of nonlinearities inherent in the KSE100 excess return series whereas the models that rejected the null were able to pick them. The reason why two out of the four models employed for testing nonlinearities were not able to find possible existence of nonlinearities in KSE 100 stock price index may have been because our time series models do not encompass features to account for possible existence of conditional heteroskedasticity and fat tails that is widely documented in the literature.

\section{CONCLUSIONS}

I employ nonlinear time series models, for finding possible existence of business cycle nonlinearities in KSE100 stock excess returns series. This approach is fully parametric and accounts for time varying volatility, outlier, and long memory that may be present in the series being investigated. In addition to switching time series models I also employed nonlinear time series models for construction of linearity test for testing nonlinearities in KSE 100 excess returns series.

Our results on linearity tests that are based on Keenan test and Ramsay RESET test provide statistically significant evidence of nonlinearities in KSE 100 excess stock returns. These results are in line with earlier study by Gabriel and Timmermann (2001) on business cycle asymmetries in stock returns. However, RESET1 test as well as RESET2 test failed to reveal statistically significant evidence of nonlinearities in KSE100 excess returns.

Our study results show statistically significant evidence of nonlinearities in KSE 100 index excess returns in two out of the four models employed for testing nonlinearities in the series. However, future research might come up with further evidence of nonlinearities (if any) in KSE 100 index using additional nonlinear time series models, possibly regime switching models with features that can account for conditional heteroskedasticity and fat tails that is documented in the empirical literature. Likewise, the use of some kind of flexible functional form of nonlinear 
time series models like artificial neural network may also be advantageous to capture nonlinearities in the KSE 100 index return series.

\section{FOOT NOTES}

${ }^{1}$ See Davis, R. (1977) and Andrews, W. (2001) for discussions on the nuisance parameter that appears under the alternative hypothesis.

${ }^{2}$ The principal component analysis (PCA) is a variable reduction technique which is designed to explain the variance-covariance structure of a set of variables through a few linear combinations of these variables (Dunteman, 1989). The PCA technique was also employed by Burkowitz, Pistor, and Richard (2003), and Durnev and Kim (2005). The PCA merely being a linear combination of existing variables might not be of much help in interpreting the results properly (Greene 2003). However, it can be helpful to understand how changes in principal components affects the dependent variable or when we are concerned about the direction of the change rather than the magnitude. Therefore, in the PCA analysis I reduce the large number of correlated independent variables into smaller number of interconnected variables that are identical number of linear combinations of existing variables that are easily interpreted (Richard and Wichern, 2002).

${ }^{3}$ Thanks are due to Dr. Tufail A. Qureshi, Editor, Business Review, for assistance with the data.

${ }^{4}$ French and Sichel (1993) and Brunner (1992, 1997) show existence of conditional heteroskedasticity in real GNP data, and Granger (1995) recommends that linearity be tested using heteroskedasticity-robust tests.

${ }^{5}$ Tsay (1988) demonstrate that nonlinearities reported in various studies are due to presence of outlier in the data. Scheinkman and LeBaron (1989) and Balke and Fomby (1994) showed that presence of outlier weakens the evidence of nonlinearities. However, Bidarkota (1999, 2000), Gabriel and Timmermann (2001) and Kiani and Birdarkota (2004) reported strong evidence of nonlinearities in macroeconomic time series even after accounting for outliers.

\section{REFERENCES}

Anderson H, Vahid F. (1998), Testing Multiple Equation Systems for Common Nonlinear Components. Journal of Econometrics, 84, 1-36.

Anderson H, Ramsey J. (2002), U.S. and Canadian Industrial Production Indices as Coupled Oscillator. Journal of Economic Dynamics and Control, 26, 33-67. 
Andreano, M. and G. Savio, (2002), Further Evidence on Business Cycle Asymmetries in G7 countries, Applied Economics, 34, 895-904.

Andrews, D., (2001), Testing when Parameter is Under the Boundary of the Maintained Hypothesis. Econometrica, 69, 683-734.

Balke, N. and T. Fomby, T. (1994), Large Shocks, Small Shocks and Economic Fluctuations: Outliers in Macroeconomic Time Series, Journal of Applied Econometrics, 9, 181-200.

Beaudry, P. and G. Koop, (1993), Do Recessions Permanently Change Output? Journal of Monetary Economics, 31, 149-163.

Bidarkota, P. (2000), Asymmetries in the Conditional Mean Dynamics of Real GNP: Robust Evidence, Review of Economics and Statistics, 82, 153-157.

Bidarkota, P. (1999), Sectoral Investigation of Asymmetries in the Conditional Mean Dynamics of the Real US GDP, Studies in Nonlinear Dynamics and Econometrics, 3, 191-200.

Burkowitz, D., K. Pistor, and J. F. Richard, (2003), Economic development, legality, and the transplant effect, European Economic Review, 47, 165-195.

Brunner, A. (1997), On the Dynamic Properties of Asymmetric Models of Real GNP, The Review of Economics and Statistics, 79, 321-326

Danielsson J. (1994), Stochastic Volatility in Asset Prices Estimation with Simulated Maximum Likelihood. Journal of Econometrics, 1994, 64, 315-400.

Davis, R., (1977), Hypothesis Testing when a Nauisance Parameter is Present Only Under the Alternative, Biometrika, 64, 247-254.

Dunteman, G., (1989), Principal Components Analysis, Sage, Newbury Park.

Durnev, A. and E. H. Kim, (2005), “To Steal or Not to Steal: Firm Attributes, Legal Environment, and Valuation,” The Journal of Finance, 60, 1461-1493.

French, M.W., and Sichel, D.E. (1993), Cyclical Patterns in the Variance of Economic Activity, Journal of Business and Economic Statistics, 11, 113-119.

Gabriel P., and Timmermann, A. (2001), Business Cycle Asymmetries in Stock Returns: Evidence in Higher Order Movements and Conditional Densities, Journal of Econometrics, 103, 259-306. 
Granger, C.W.J. (1995), Modeling Nonlinear Relationships Between ExtendedMemory Variables, Econometrica, 63, 265-279.

Greene, W. H., (2003), Econometric Analysis. Upper Saddle River, NJ PrenticeHall.

Judge, G., Griffith, C. Hills, H. Lutkepol, and T. Lee, (1985), The Theory and Practice of Econometrics, $2^{\text {nd }}$ edition, Wiley: New York.

Jensen, D., and de Vries, C. (1991), On the Frequency of Large Stock Returns: Putting Booms and Busts into Perspective. Review of Economics and Statistics, 73, $18-24$.

Keenan, D., (1985), A Tucky Nonlinear Type Test for Time Series Nonlinearities, Biometrika, 72, 39- 44.

Kiani, K., P. Bidarkota, and T. Kastens, (2005), Forecast Performance of Neural Networks and Business Cycle Asymmetries, Applied Financial Economics Letters 1, 025-210.

Kiani, K., (2005), Testing Nonlinearities in Using Time Series Models and Artificial Neural Network, Computational Economics 26, 65-89.

Kiani, K., and P. Bidarkota, (2004), On Business Cycle Asymmetries in G7 Countries, Oxford Bulletin of Economics and Statistics, 66, 333-353.

McQueen, G., and Thorely, S., (1993), Asymmetric Business Cycle Turning Points, Journal of Monetary Economics, 55, 703-708.

Neftci, S., (1984), Are Economic Time Series Asymmetric Over the Business Cycle? Journal of Political Economy, 92, 307-328.

Potter, S., (1995), A Non-linear Approach to U.S. GNP, Journal of Applied Econometrics, 10, 109-125.

Ramsey, J., (1969), Tests for Specification Errors in Classical Linear Least-squares Regression Analysis, Journal of the Royal Statistical Society, 31, 350-371.

Ramsey, J., and Rothman, P. (1996), Time Irreversibility and Business Cycle Asymmetry, Journal of Money Credit and Banking, 28, 1-21.

Richard A.J., and Wichern, D.W., (2002), Applied Multivariate Statistical Analysis, Prentice Hall, Upper Saddle River, New Jerssy. 
Scheinkman, J., and LeBaron, B., (1989), Non-Linear Dynamics and GNP Data, Cambridge: (Cambridge University Press Cambridge).

Schwarz, G., (1978), Estimating the Dimension of a Model, Annals of Statistics, 6, 461-4.

Tsay, R., (1986), Nonlinearity Tests for Time Series, Biometrika, 73, 461- 466.

Table 1: Linearity Tests Results: Nonlinear Time Series Models

$\begin{array}{lll}\text { Test Type } & \text { Test Statistics } & \text { p-values }\end{array}$

Ramsay RESET Test $\quad 1.83685 E+28 \quad 0.0001$

$\begin{array}{lll}\text { RESET1 Test } & 2.31750 \mathrm{E}+00 & 0.1294\end{array}$

$\begin{array}{lll}\text { RESET2 Test } & 3.52230 \mathrm{E}+01 & 0.9999\end{array}$

\section{NOTES ON TABLE 1}

1. Table show linearity test results based on Keenan test, Ramsay RESET test, and its improved version RESET1, and RESET2 test. The empirical models used for calculating the test statistics reported in this Table are shown in Equations 2.1 to 2.8 in the preceding text. 
2. In this Table for example column 2 row 1 show test statistics for Keenan test and column 3 row 1 presents p-values for this test. The results for the remaining tests are presented in a similar manner.

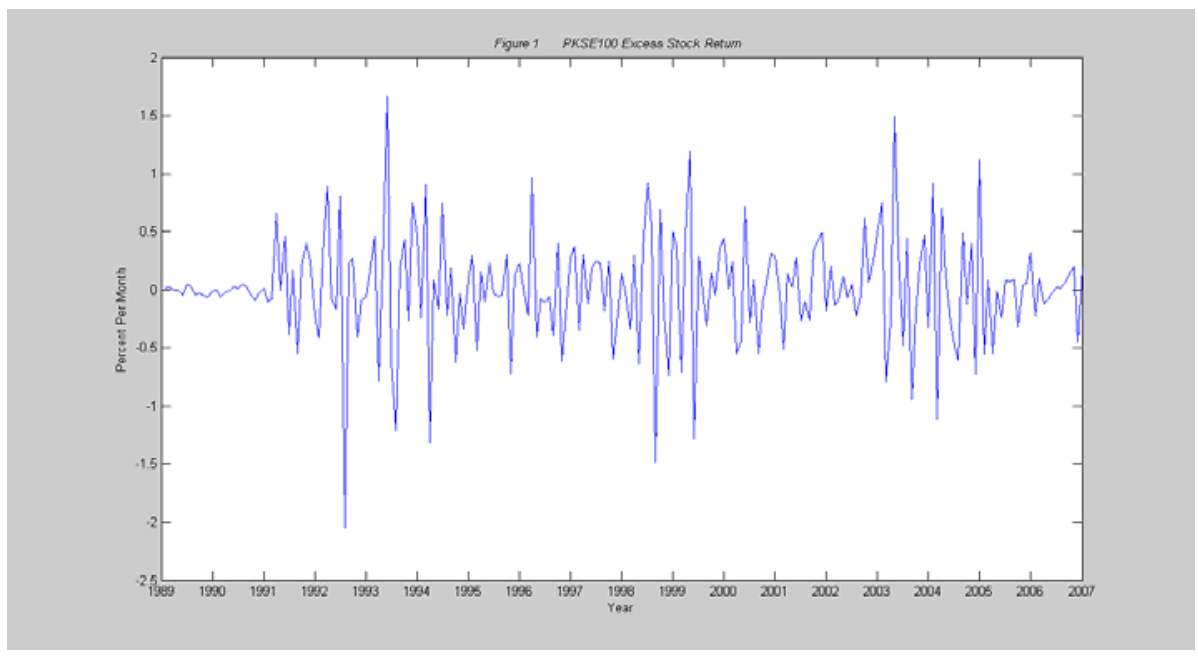

Sometimes when I consider what tremendous

consequences come from little things.......

I am tempted to think ..........

there are no little things. 